\title{
U50 Small Nucleolar RNA
}

National Cancer Institute

\section{Source}

National Cancer Institute. U50 Small Nucleolar RNA. NCI Thesaurus. Code C131745.

U50 small nucleolar RNA (75 bases) is encoded by the human SNORD50A gene. This oligoribonucleotide plays a role in the methylation of ribose in preribosomal RNA. 